\title{
AS THE WORLD TURNS: A GLIMPSE INTO DISTANCE EDUCATION
}

\author{
Kristi Berg, Minot State University, kristi.berg@ndus.edu \\ Paul Bujak, Minot State University, paul.bujak@ndus.edu
}

\begin{abstract}
As the world turns so too has the field of distance education. Advances in information technology and systems command attention from all industries and create demands from consumers. Remaining competitive in today's society requires consumers to learn more and more, meeting this demand calls for accessible, swift and just-in-time learning methods and tools. This paper highlights several tools and their uses as the distance education landscape continues to turn.
\end{abstract}

Keywords: Distance Education, MOOCS, LMS, Boot Camp and Training Portal.

\section{INTRODUCTION}

Distance education has come a long way from the days of a mail order program consisting of books and proctored exams. Students enrolled in distance education programs in the past were mainly interested in obtaining a new skill to meet a work demand, thus distance education was viewed as a business transaction, a no where near equivalent to what the classroom could offer. Today's programs combined with the internet and wide variety of educational offerings reach individuals interested in hobbies all the way to full degrees that can be completed entirely online. Such programs are rich in methodology, professionalism, relevancy and content. The mail order programs of the past had nowhere near the currency or responsiveness of today's distance education programs, had trouble gaining acceptance and were viewed as poor excuses for the real thing. Modern day explosions of technology have led to vast and changing demands of learning from the population at large.

\section{MASSIVE OPEN ONLINE COURSES (MOOCS)}

In order to facilitate an ever growing demand for knowledge many universities launched open courseware and Massive Open Online Courses (MOOCS). Individual course offerings morphed into allowing learners to earn a certificate, sometimes even for no cost, to educational providers linking courses with full degree programs. All in an attempt to build an educational infrastructure to help workers that might be reorganized or displaced by technology in the coming years, provide an opportunity for continuing education and career advancement, allow for flexibility of location and to retain income while improving oneself (Economist, 2017).

A MOOC is an online course that allows for unlimited participation with access via the web (Kaplan, Haenlein, 2016). These courses first came to fruition in 2006 and started to become very popular around 2012. Since that time MOOCs have increased at an ever-faster pace as depicted in Figure 1 and culminating in what are now MOOC courses that are done in sequence to create online distance degrees. Examples of this include a University of Illinois MBA and Master of Science Data Science program through the MOOC Provider Coursera (Coursera, 2017). This looks to be a potential model for universities to follow due to the robust course offering with continuously refreshed curriculum. This creates continuous course latency in which the information, content and educational value is relevant to the skills sought after by employers, while providing an ever-increasing layer of courses based on new in demand genres. 


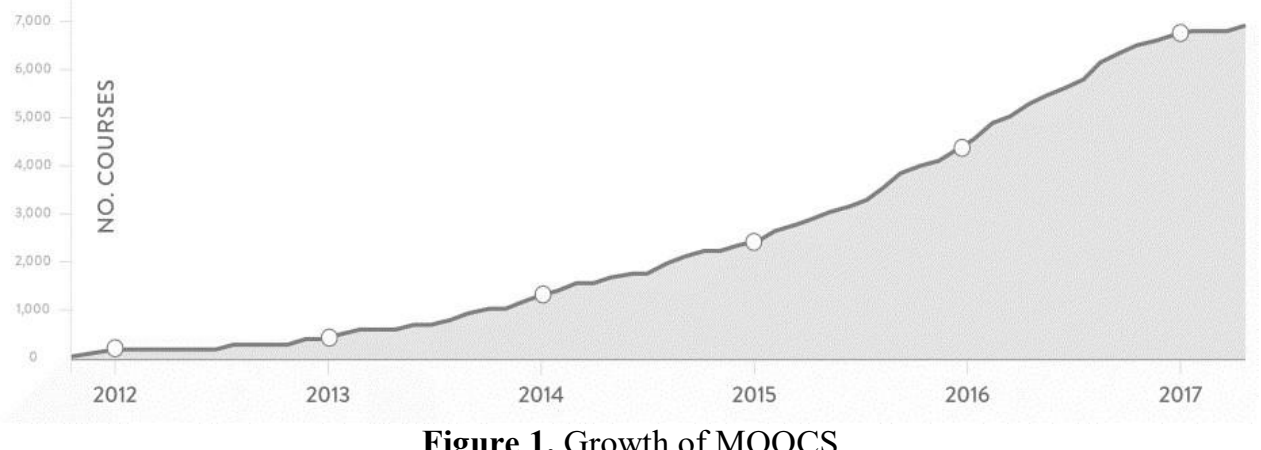

The original mission of the MOOC movement was to open up what was once considered a closed end process (Pappano, 2014). Many of the worlds most respected universities and Ivy League institutions started posting their most sought after courses. This has been followed by more of a global presence from universities that are typically featured within the QS World top 200 list of the best universities in the world. The openness of such education has led to many individuals subscribing to these courses but few finishing. This will definitely pose a challenge in the future for educational institutions that are looking to provide results or outcome based education programs. In response to this situation increased costs and course certifications and verifications are being offered. The theory of this approach seems to go with the idea that if one is paying for the course they have "skin in the game" (Yuan, Stephen, 2013). Results are not conclusive that this method is working as it had been intended to work.

\section{Learning curve}

Massive open online courses, main international providers

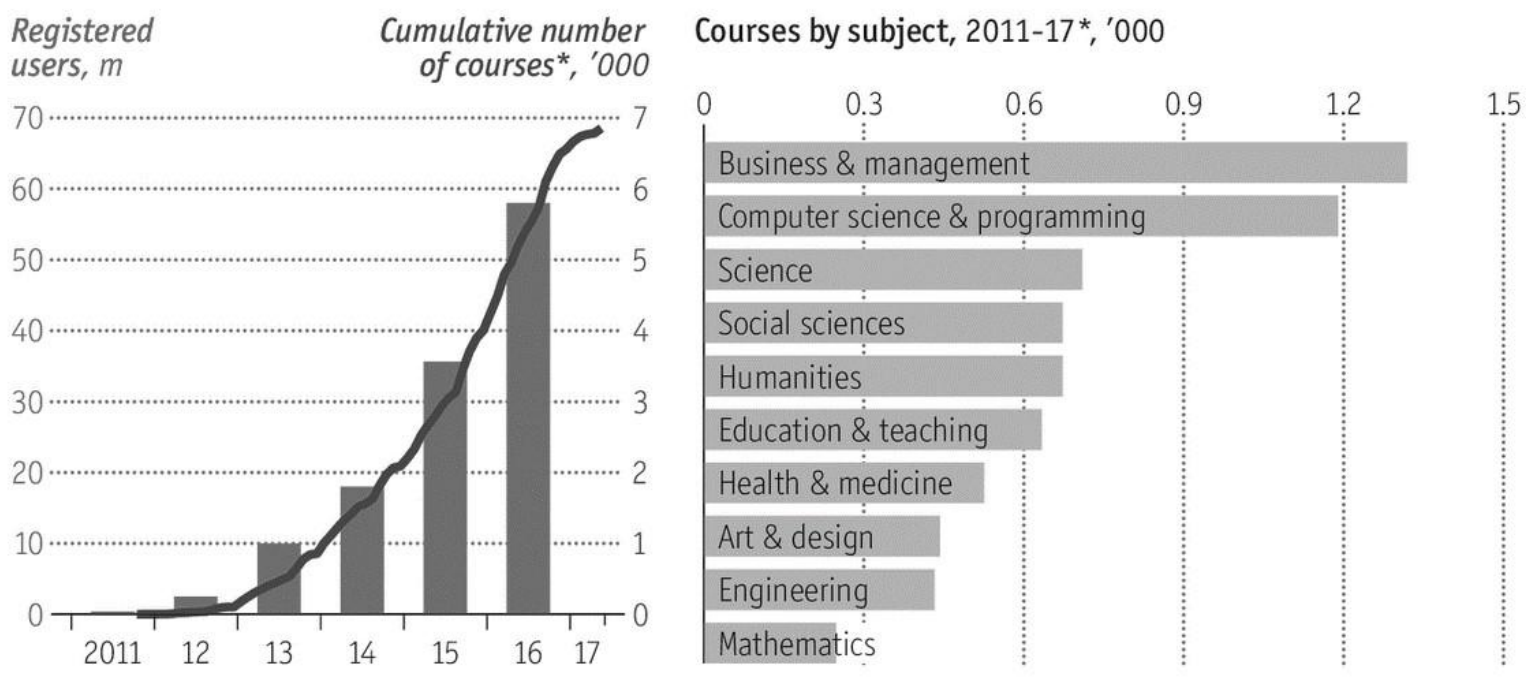

Source: Class Central Economist.com

Figure 2. MOOCS Learning Curve

Massive Open Online Course providers are not only growing as demonstrated in Figure 2, but the type of provider is growing as well. Individuals with developed expertise are increasingly joining the course development process. As these individuals with developed skills join in on the development of MOOCS the list and availability of learning opportunities will become exhaustive in itself. The key element to remember despite the growth of these course is that there should be a focus on outcome, availability, relevance and lifelong learning. Opening up educational opportunities will allow individuals to continuously pursue the lifelong learning that is increasingly becoming the standard in terms of building skills that are required within the employment arena. As requirements of the workplace gather pace the 
relevance of a continuous learning platform that is provided through organizations like Coursera or EdX will only grow and continue to extend beyond traditional methods (Yuan, Stephen, 2013).

The two most prominent types of course that are offered via MOOC platforms are business and coding based courses. This can be traced to the fact that there is a continuous demand for such skills worldwide. Secondly the acute perceived or unperceived shortage of tech workers with skills in various technology genres continues. This is particularly seen with the realm of software engineers, programmers, and web developers. Therefore many MOOC providers have developed or launched course offerings that are geared towards these types of technological genres and their popularity has continued to grow. In the near term this trend looks to continue as both business and coding positions remain highly compensated as well as available. One of the new growth trends is that of engineering course popularity however it is not likely to overtake the popularity of business and coding courses (Coursera, 2017).

\section{MOOC Providers}

The half decade old MOOC industry includes over 55 million students, 700 universities and 6000 courses. The following is a look at a several of the top providers as of 2016.

\section{Coursera}

Coursera is a Massive Open Online Content portal that is designed in junction with the leading universities of the world. The types of courses that are available have much greater breadth in genres than most MOOC portals. Coursera prides itself on having top faculty and universities creating programs in the most relevant fields. There are usually several courses within each certificate that one needs to take. All courses need to be passed with an $80 \%$ percent or higher grade. Coursera is available on multiple platforms including smartphones, laptops, tablets, and desktop computers.

\section{EdX}

EdX is a portal that is similar to Coursera that offers respected universities and industry partners to post courses in a variety of academic genres. There are more than 90 different partners that EdX works with in collaboration on learning projects. The goal of EdX was to also work on making quality education from top schools accessible to the world where the internet is connected. EdX was founded by Harvard University and MIT in 2012 to continue on building access to online learning for various platforms.

\section{Futurelearn}

Is owned as a private company within Open University based in the United Kingdom which in its own right has 40 years as an institution providing programs through distance education. Futurelearn has many well-respected universities offering courses and certificates online within many different topics. Futurelearn like EdX does work with many partners as well in the creation of courses. The first courses within this MOOC portal that were launched were in the year 2013, and every year the amount of courses available has grown.

\section{Udacity}

Udacity is focusing on being one of the most accessible, affordable, engaging, and highly effective higher education in the world. That is the ultimate goal of providers of education via MOOCS. The end goal of Udacity is building an online University that is affiliated with various leading Universities and companies to create focused degrees on relevant genres of web development, data analysis, machine learning, robotics, mobile developers, digital marketing and other high demand fields. Udacity was founded by Sebastian Thrun at Stanford University as an experiment in developing a platform that is to bridge the gap between real world skills education, and employment.

In addition to MOOC providers a marketplace has popped up enabling learners the opportunity to shop around as one does when booking an airline ticket. The following provide an example of such providers.

\section{Udemy}

Udemy started as a Massive Open Online Content platforms that has turned into a marketplace for learning teaching various relevant skills. Udemy has had similar goals as many of the MOOC providers, it has wanted to make quality education available to many individuals that have access to the internet. The founder Eren Bali felt very frustrated growing up in Turkey with the limited available content for one to learn. The resulting solution to the lack of content 
available was Udemy. One can typically buy almost every type of course and genre that is known. The breadth and depth of the availability is very large so is the price range.

\section{Skillshare}

SkillShare takes a much different approach than Udemy to Massive Open Online Learning or MOOCs by instead of having to purchase courses individually one purchases access via monthly or yearly subscription. This allows one to access all courses online, as well as open access to all courses that are available. The goal of this website is to allow students to work at their own pace, develop skills, and open up career prospects. Skillshare allows for anyone to develop a course and post it within the community.

\section{Learning Management Systems}

In addition to MOOCS comes Learning Management Systems (LMS). Although the LMS was not entirely new to educational institutions, a new form can be said to have appeared in the last few years. Internally, educational institutions were developing and using grassroots LMS. As these took hold and demand increased designers pulled together the vital and most crucial elements and the LMS industry took off. These systems function as a portal for both education and business learning needs. Educational institutions are able to offer their courses and degrees online for use with campus and distance learners, while business and industry can offer up-to-date training while employees are on the job. Adaptability and personalization of learning is desirable and LMS has provided a foundation to meet such demand (Rangwala, 2017).

The LMS has been the staple of corporate educational and used to direct the type of teaching experienced (Ellis, 2017). LMS have been implemented as corporate directives in assignment of learning activities of employees. As complexities from the various business situations have grown so to have the requirements of employees to learn what is critical for success in the job roles that they hold.

LMS have also served as the hallmark of non-business learning which in turn has turned the classroom from a physical location to a virtual one (Ellis, 2017). Many universities utilize the Blackboard system to host a variety of online courses that culminate to a certificate and/or a degree. Other types of platforms that may be used in this type of program include Canvas, Moodle, and Desire2Learn. As demand for such types of programs will grow over time new systems to compete with established platforms will surely arise especially as outcome based approaches will become the norm (Oxagile, 2017).

What LMS allow educational providers whether they are business and educational institutions is to structure content and disperse knowledge in a structural manner. This provides students with a step by step learning mechanism in which learning is broken down in to digestible pieces. Most of the LMS are Software as a Service (SaaS) where by the hosting is provided by the vendors for a monthly subscription that is based off users or all-inclusive package within the cloud (Sharma, 2013). Systems such as these have helped educational institutions reach more students while allowing more students a flexible working arrangement (Ellis, 2017). This is not only a U.S. based phenomenon, it has an international reach due to the accessibility of courses via the Internet. Being able to provide courses online has also allowed students that have the qualifications to partake in established and accredited universities that once would have required traveling to the universities particular location.

The domain of the LMS has grown to accompany the individual consumer and small business owner as well in recent years. This is through the development of LMS that are portals where users can subscribe to the LMS for a monthly fee and access thousands of courses online and through mobile devices. These are ideal for individuals that want to learn from anywhere and have the drive to accomplish such learning endeavors. The growth of these portals will continue as the need to develop many skills in order to be competitive within the work place becomes acute. The potential is very large for LMS because of the fact that more and more skills will be required of the workforce. In turn opportunities will arise for entrepreneurs, educators, incumbents and individuals to develop systems that will impact learners from the earliest of ages all the way to mature learners. The LMS marketplace has grown considerably, the following are examples of LMS providers. 


\section{Blackboard}

Blackboard is a provider of various different platforms for the educational market, as well as government and business. Blackboard can be deployed onsite through servers or through a SaaS. Another option is that if the blended learning model to personalize the learning experience for learners. There is even an open source platform that is available with Blackboard called Moodlerooms which was designed in partnership with Moodle. Blackboard is a leader in the field of LMS.

\section{Moodle}

Moodle is the open source platform that allows institutions whether business, educational and governments to build their own LMS. There are also partners that can help enhance the types of applications that can be setup within Moodle. One can simply download the software and start building a learning environment for whatever learning that needs to be completed. The nice feature is that there is no cost in obtaining a license for Moodle and that the platform is very scalable.

\section{Canvas}

Canvas is a solution like Blackboard but from a much newer company that was founded in 2008 with the goal of making LMS better. The focus is on the various features over a thousand that educational institutions use in order to build a highly-customized LMS. The other factor that is user experience and whether students will use the platform. Many institutions have gone to use Canvas for the reason that it is a system which is easy to use and can be truly built to the needs of the educational institution.

\section{Desire2Learn}

Another Learning Platform that can be used by businesses and educational institutions is Desire2Learn (D2L). This platform provides the ability for classes to be built or use of the content that is developed by the institution whether educational or business. There is a strong emphasis on analytics within the Desire2Learn system which can help educators best decide how to help students learn. D2L is designed to provide varied engaging learning in order to keep student interest by providing an appealing graphical interface.

\section{PluralSight}

PluralSight is a new realm of educational LMS. It is a platform that hosts courses that allow the individual or business purchase access to 5000 plus courses based on a variety of technical and business genres. Instead of purchasing a course on prepping for the Project Management Professional certification a learner can, for \$29.00 dollars a month, purchase all access to a large and diverse body of courses. The content is developed both by Plural Sight and individual course developers.

\section{Learn Smart}

A similar Learning Management System to PluralSight is that of LearnSmart. This Learning Management System is one in which course content is developed by Learning Smart and sold in a bundled package to individuals and businesses. The breadth and depth is also within the same lines in which technical and business course are developed for learners wanting to obtain new skills and certifications.

\section{Udemy Business}

Udemy Business is part of the original Udemy Online Learning Management System. The difference is that Business can buy a subscription to all the courses that are available. All content is developed by individual content creators, and the breadth and depth of courses spans many genres outside business and technical skills. Udemy Business provides a cost effective solution for business looking to develop the skills of employees.

\section{Boot Camps}

Boot Camps are another form of distance education which are on the rise as shown in Figure 3 and have come to symbolize a potential rapid solution to the shortage of technology workers. These provide the individual with a chance to get in the front seat of the ever-expanding technology boom (Robinson-Avila, 2017). Boot Camps primarily cater to web development, app development, full stack software engineering, product management, user interface/user experience, data analysis and data science. Boot Camps generally have experienced developers on their staff as mentors. This type of education is very immersive requiring students to complete several projects while intensively learning several programming languages. The end goal is to get someone that is not a developer up and running within 


\section{Issues in Information Systems \\ Volume 18, Issue 4, pp. 169-178, 2017}

8 to 12 weeks. Then into a developer job within 2 to 6 months. Many students participate in these programs not only because of the prospects of a job but because these boot camps boast high percentages upwards of $80 \%$ employment after graduation (Robinson-Avila, 2017).

Boot Camps are a relative new direction in the education sphere which tries to develop students into capable workers within a short time span (Choxi, 2017). These courses are designed to be vocational in nature teaching students the skills and requirements of a particular job or position depending on the program that the student has chosen. Most platforms operate a dual based classroom and online learning experience for students. Meaning that the students themselves can choose to go to an immersive program that is classroom based or one that it based online (Choxi, 2017). Many of the top boot camps expect that students put in long hours to solve technological programming challenges.

Most boot camps are technology based and require students to learn to program in a variety of languages in order to properly function in their new roles after the program. The challenges that boot camp providers place on students include learning the foundations of development of applications, as well as getting up to speed on what a software developer will need to do on a daily basis. Boot camp programs have relatively a very high selection criteria for those whom want to enter these programs. There are pre-boot camp courses available that allow students to prepare for the total boot camp process. Essentially such courses give students the overview of the programming languages that they will be using in order to accomplish the challenges within an upcoming boot camp (Choxi, 2017). The challenging curriculum requires students to develop fully functioning applications that are clone existing applications and/or a capstone project requiring students to develop their own application. These challenging projects are designed to be portfolio highlighting pieces to help students obtain positions within companies looking for software engineers or developers. Boot camps are direct competitors of college degrees and could possibly become part of a college curriculum (Skonnard, 2015).

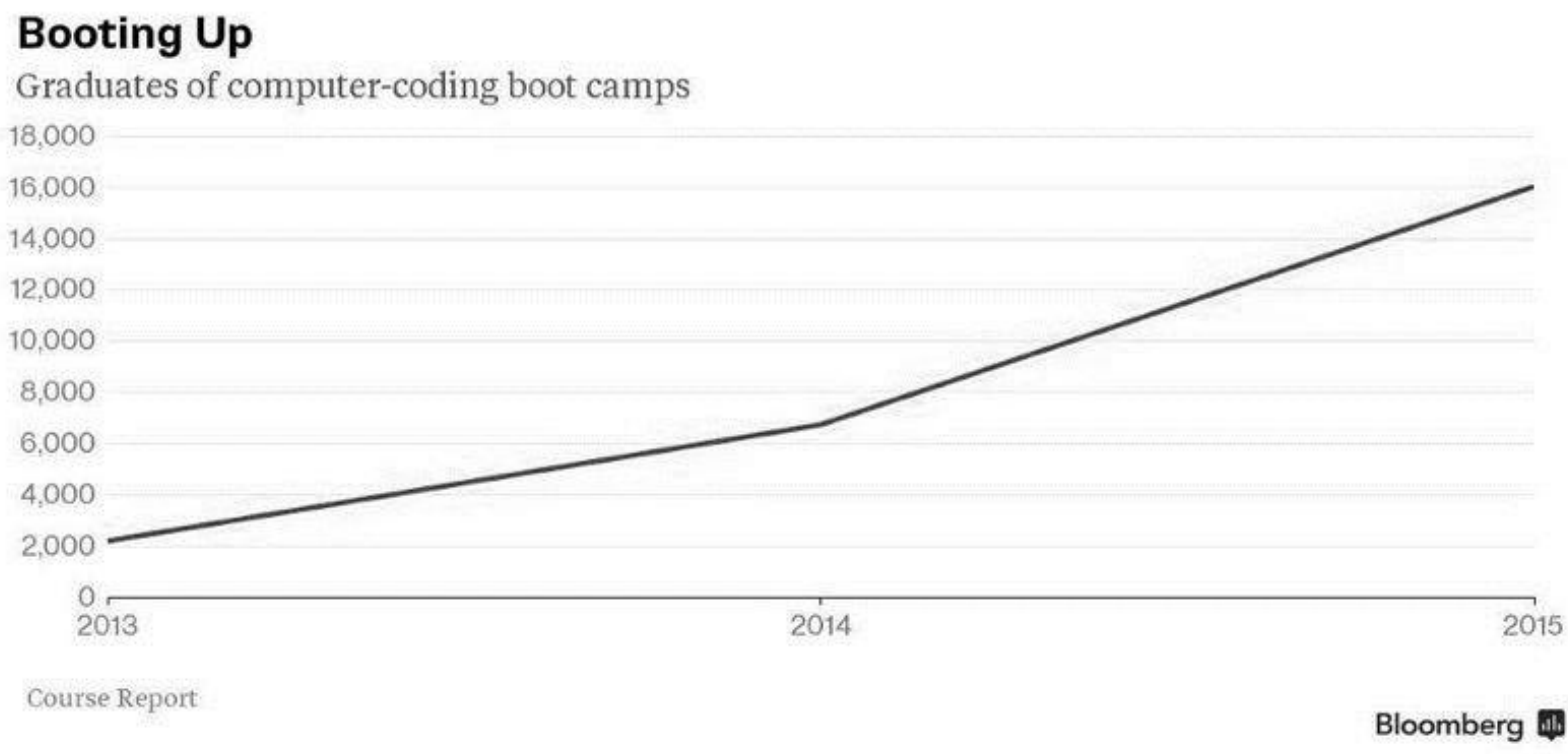

Figure 3. Boot Camp Growth

Throughout the process of a boot camp students are mentored by an individual that is a successful software engineer and or developer. These persons provide the guidance on how a student should develop their skills in order to be successful within their potential future roles as developers and engineers as well. One of the key aspects of this process is that mentors impart knowledge of the real challenges that students will likely face on the job (Skonnard, 2015). Finally, mentors train their students how to pass technical interviews after they complete the boot camp program. Learning how to interview for technology jobs is a much different method in practice than interviewing for a nontechnology position. 
Recent developments have sparked a renaissance with vocational training for the factory jobs of the future. These programs in conjunction with local colleges and businesses have sprung up in order to facilitate the industrial revolution 4.0, the industrial Internet. These boot camps or as they can be called training programs teach hands on experience in operating systems within in the factory of the future. Part of this training as well includes programming for the industrial technologies that are developed for the new 4.0 revolution. Companies like General Electric, Siemens, Caterpillar and BMW are sponsoring programs that get workers ready for the factories that will be built in the future (Berliner, 2014). Many employers including the ones mentioned have mentioned the lack of talent that is available for the jobs of the future. Jobs that are able to program industrial 3 dimensional printers that will print parts to cars, engines, trains, and other products. Other positions would include programming robots for entire lines of production at a local plant. Boot camps in the future will allow workers to quickly learn different aspects of future jobs much more quickly than a regular degree. The focus will also be one the relevancy of the training and not just mere theory. Workers will have to be read to jump into the various roles of the future, without remedial training being done on the first day of work.

\section{Boot Camp Providers}

Several Boot Camp providers exist in the marketplace and are ready to deliver their services. The following are examples of such providers.

\section{BLOC}

BLOC is an online and classroom based boot camp that teaches students technology based skills within a short time frame generally 12 weeks or 3 months. There are a variety of different tracks that one can take with this boot camp program. Students can become educated in Web development, Software Development, and Design. The programs most intensive tracks Software and Design are done within a classroom environment. While the Web Developer track is completed on a part time basis online within a 27 week or 6 month period. Among the challenges is the one needs to intensely learn how to program within a short amount of time.

\section{New York Data Science Academy}

A Newer field within the Boot Camp realm is that of Data Science and Data Analytics these programs allow students to be immersed all things data, from the programing of Python and R, to actual projects applying Machine Learning. Data Science Boot Camps operate very similarly to that of coding boot camps, but the focus is much narrower topic of learning how to obtain, process, correlate, and present data. There are two tracks available in this program one online and the other classroom based. The classroom based program is fulltime intensive, while the online program can be taken fulltime or part time.

\section{General Assembly}

A program that has many elements of both a coding and data science camp but additional types of tracks is that of General Assembly. There are five different tracks that one can take in this program ranging from coding all the way to Product Management. General Assembly operates boot camps in many cities through the United States and has been opening locations around the globe. Course are both taught online and in a classroom environment, however online offerings are fewer than what is available to take in the classroom. Online courses are self-paced while classroom based courses are intensive. There are also mentors that help students adjust and problem solve tasks.

\section{Coder Camps}

Coder Camp is a boot camp that focuses on the training of software developers and doesn't include other programs such as design or data science. Learners can choose from online and classroom based camps. The online program has a 2 day capstone on site course program, which is designed to give students that extra bit of help in learning the process of being a software developer. Coder Camps programs classroom base learning is done in 12 weeks or three months. While the online program is completed in 24 weeks which is under 6 months.

\section{Training Portals/Courses}

Training portals or courses provide the means for one to be able to individually subscribe to a portal and or website that has updated courses in various learning genres. A training program like Codecademy is a true educational reformer rethinking education bottom up (Mclaughlin, 2015). Many of the well-known training websites are very focused on 
the technology genre of learning. Examples of this include web development, software engineering and/or mobile development. These training websites/portals are often viewed as a modified boot camp that offers a limited enrollment and a specific time frame. The modified training course does provide mentors and support similar to a boot camp. Training websites try to provide a relatively inexpensive model of learning for technology oriented jobs that are more Information Systems and Information Technology based. These training courses also provide many courses for free to learn at your own pace style (Mclaughlin, 2015).

Training courses and that of online websites that feature such courses are designed for the learner who is wanting to develop and learn skills on their own (Perez, 2013). The programs have a hybrid feel to them as they can be seen as a cross between a boot camp, LMS, and MOOC. These programs offer all kinds of different approaches to gain new skills. Most operate on a subscription basis and have a focus to train students at their own pace. Three examples of popular training classes include:

\section{Codecademy}

Codecademy is an online website that offers free and paid based subscriptions to learning environments and courses to individuals who desire learning at their own pace. Codecademy recently launched a program that is called Codecademy Pro which offers a self-paced boot camp experience. The program allows one to learn a full stack of technologies that lead to a software developer or engineer skills. All major programming languages are covered within the program and there are many hands on projects to complete in order to build one's portfolio.

\section{DataCamp}

A similar program to that of Codecademy is that of Data Camp, which focuses on data analysis and data science learning. There many different courses that one can choose from in terms of data science from learning how to apply Python programing to financial markets or analyzing healthcare data. There are two tracks in which one can learn to program for data science R programming or Python Programming. Through this self-paced program students learn to develop the skills of a true data scientist.

\section{One Month}

This training website has a different aspect to training altogether through an almost hybrid approach of a training course and boot camp. The difference is that all skills are to be learned in the time frame of one month. Instead of jumping into the full programming spectrum and learning to do everything, one type of skill is focused in a month's time. Students can pursue multiple tracks if they would like to choose that path the intensity of the program is dependent on how many courses a student decides to take. There are a variety of paths one can from growth hacking all the way to all programming languages.

\section{CONCLUSION}

Learning online will become an ever-increasing portion of the learning curriculum individuals will be pursuing whether it be degree programs or lifelong learning new types of skills in the process. One thing that is for certain is that members of society will have to increasingly learn more in order to be a contributing member of society. Not only will individuals have to learn more but they will have to learn faster and be able to garner insights that are assisted by artificial intelligence (Burroughs, 2017). This will lead to more and more information being thrown at individuals requiring ever intense learning of new subjects and methods. One of the goals for future research could be to find the ideal methods in learning at ever increasing speeds.

Part of this process can be the research of unfold the reasoning behind students not following through on the all the courses that they are enrolled in on a website like Coursera. How do we get students to increasingly complete those courses? Also, how do we ensure that students are learning relevant topics to enhance their marketability to employers? Enhancing the significance of the research would be an attempt to time this information to how this new wave of education is helping bridge gaps in economic quality? Finally, how is this educational revolution requiring students to learn much quicker in order to keep pace with the information processing requirement? Are humans actually evolving evolutionary enhance traits due to the ever-increasing requirements that are being place upon them?

The future of these courses is one in which a blend of learning methods in Education 3.0 growing and enhancing the future student's ability to learn from the various sources. A more contradiction of convention will impact the way 


\section{Issues in Information Systems \\ Volume 18, Issue 4, pp. 169-178, 2017}

future students will be learning verses how learning is completed today (Burroughs, 2017). Particularly there will likely be a system that is in place that will allow for students to be given real-time assessments with Artificial Intelligence pointing students towards the right direction in learning or helping them to overcome any of the challenges that they may have. This in theory should help students become much better learners that have a better grasp of the topics to learn. As we explore how the future of education 3.0 is to be shaped ideas will come to mind on potential outcomes of this exciting new field. Open-mindedness will continue to be a path that will enlighten one's ability to grasp the rich future methods that will allow for society to move forward.

\section{REFERENCES}

Berliner, U. (2014, November 06). In South Carolina, A Program That Makes Apprenticeships Work. NPR. Retrieved April 10, 2017, from http://www.npr.org/2014/11/06/361136336/in-south-carolina-a-programthat-makes-apprenticeships-work.

Burroughs, A. (2017, April 21). Q\&A: Artificial Intelligence Expert Shares His Vision of the Future of Education. Retrieved April 01, 2017, from http://www.edtechmagazine.com/higher/article/2017/04/qa-artificialintelligence-expert-shares-his-vision-future-education.

Choxi, R. (2015, November 08). Coding bootcamps are replacing computer science degrees. Retrieved April 10, 2017, from https://venturebeat.com/2015/11/08/coding-bootcamps-are-replacing-computer-sciencedegrees/.

Ellis, R. (2009). A Field Guide to Learning Management Systems. Learning Circuits, 1-8. Retrieved February 02, 2017, from http://www.astd.org/ /media/Files/Publications/LMS_fieldguide_20091.

Kaplan, A. M. (2016). Higher education and the digital revolution: About MOOCs, SPOCs, social media, and the Cookie Monster. Business Horizons, 59(4), 441-450. Retrieved March 03, 2017, from http://www.sciencedirect.com/science/article/pii/S000768131630009X.

Mclaughlin, M. (2015, May 28). Codecademy. PC Magazine. Retrieved March 03, 2017, from http://www.pcmag.com/article2/0,2817,2484745,00.asp.

Pappano, L. (2012, November 02). The Year of the MOOC. The New York Times. Retrieved February 28, 2017, from http://www.nytimes.com/2012/11/04/education/edlife/massive-open-online-courses-are-multiplyingat-a-rapid-pace.html?pagewanted=all\&_r $=0$.

Perez, S. (2013, January 02). Developer Training Platform Pluralsight Raises \$27.5 Million From Insight Venture Partners To Expand Its Online Catalog. Retrieved April 10, 2017, from https://techcrunch.com/2013/01/02/developer-training-platform-pluralsight-raises-27-5-million-frominsight-venture-partners/.

Rangwala, M. (2017, April 15). Why Learning Management System is useful for all students. Retrieved March 29, 2017, from https://yourstory.com/2017/04/learning-management-system-advantages/.

Robinson-Avila, K. (2017, April 10). Coding boot camps boost career potential. Retrieved April 15, 2017, from https://www.abqjournal.com/985180/coding-boot-camps-boost-career-potential.html.

Sharma, A. (2013). The History of Distance Learning and the LMS. Retrieved February 28, 2017, from http://www.elearnhub.org/the-history-of-distance-learning-and-the-lms/.

Skonnard, A. (2015, October 29). Edtech's Next Big Disruption Is The College Degree. Retrieved April 10, 2017 , from https://techcrunch.com/2015/10/29/edtechs-next-big-disruption-is-the-college-degree/. 
Issues in Information Systems

Volume 18, Issue 4, pp. 169-178, 2017

Yuan, L., \& Powell, S. (n.d.). MOOCs and Open Education: Implications for Higher Education White Paper. JISC cetis Centre for educational technology \& interoperability, 1-21. Retrieved April 13, 2017, from http://publications.cetis.org.uk/wp-content/uploads/2013/03/MOOCs-and-Open-Education.pdf. 